\section{Neurological findings in early syphilis: a comparison between HIV positive and negative patients}

\author{
Alejandra González-Duarte, 1 \\ Zaira Medina López² \\ 1Department of Neurology and \\ Psychiatry, National Institute of Medical \\ Science and Nutrition Salvador Zubirán, \\ Mexico City; ${ }^{2}$ Central Military Hospital, \\ Mexico City, Mexico
}

\section{Abstract}

After a decade of steady decline, syphilis has reemerged within the past few years and it is seeping back into the HIV negative population. We describe herein 16 consecutive cases of neurosyphilis and compare its clinical characteristics. Of the 16 patients, 14 (87\%) were men. Mean age at onset was 43 years old (range: 23-82). Twelve patients (75\%) were HIV positive; stage was B2 in 2 patients, B3 and $\mathrm{C} 2$ in one patient each, and $\mathrm{C} 3$ in 8 patients. The clinical presentation was meningitis in $6(40 \%)$, stroke in $3(18 \%)$, ocular manifestations in $4(27 \%)$, and psychiatric manifestations in 2 (13\%) cases. Five additional patients had ocular involvement after a formal ophthalmologic examination. High venereal disease research laboratory test (VDRL) titers in serum and cerebrospinal fluid (CSF) were found. Patients in C3 stage of HIV had less CSF pleocytosis $\left(<5\right.$ cells $\left./ \mathrm{mm}^{3}\right)$ than patients in earlier stages $(\mathrm{P}=0.018)$. Disease onset was earlier in patients older than 50 years old with HIV ( $\mathrm{P}=0.049)$. We found that meningitis, ocular manifestations and stroke were the most common clinical findings in early syphilis. Moreover, stroke included the carotid and cerebrobasilar vascular territories. CSF VDRL continues to be a crucial test in all idiopathic cases of meningitis, stroke and uveitis, regardless of the HIV status or CSF pleocytosis. Except for less pleocytosis, there were no important differences between HIV positive and HIV negative patients.

\section{Introduction}

After a decade of steady decline, syphilis has reemerged within the past few years and it is seeping back into the HIV negative population. ${ }^{1}$ The fluctuation on its incidence around the world has raised the concern about the central nervous system invasion. ${ }^{2}$ Unfortuna - tely, the clinical and laboratory diagnosis of neurosyphilis is complex. Early invasion of the central nervous system (CNS) by Treponema pallidum, the causative agent of syphilis, is thought to occur in most patients within days after exposure. Typical neurological manifestations include acute meningeal syphilis, meningovascular syphilis, paretic neurosyphilis, and tabetic neurosyphilis. ${ }^{1-3}$

The diagnosis of neurosyphilis based on ocular findings is often elusive because of the various presentations. Ocular syphilis is considered an uncommon manifestation of syphilis. However, it can be the only manifestation in patients with neurological involvement.1,3,4 The most common ocular manifestation is uveitis, but a multitude of other presenting signs have been described in both human immunodeficiency virus (HIV)-positive and HIV-negative patients.

Most of the large series of neurosyphilis were reported in the pre-penicillin era, when serological tests and therapy differed, hindering the extrapolation of some results. ${ }^{3}$ The majority of new cases around the world are reported in HIV-infected patients, but the epidemiology of modern neurosyphilis is not well defined because of the paucity of populationbased data. ${ }^{3}$ We aim to report the clinical manifestations and laboratory data of 16 (4 nonHIV) cases of neurosyphilis.

\section{Materials and Methods}

We reviewed all the medical records of the patients with the diagnosis of syphilis or neurosyphilis from 1989 to 2010.1-9 Neurosyphilis was defined as a positive non-treponemal test (VRDL) followed by a fluorescent treponemal antibody-absorption (FTA-Abs) test in the cerebrospinal fluid (CSF). Serum VDRL, HIV status, CSF characteristics on presentation, neuroimaging, treatment, and outcomes were registered. CSF parameters were considered abnormal when leukocyte count was above 5 cells $/ \mathrm{mm}^{3}$, and proteins were above $40 \mathrm{mg} / \mathrm{dL}$. In addition, in patients with HIV, we determined the most recent $\mathrm{CD} 4+$ cell count at neurosyphilis onset and clinical stage according to the Centers for Disease Control and Prevention (CDC) criteria. Clinical improvement was considered to have occurred when there was partial or total improvement documented by the medical staff.

The statistical analysis was performed with the SPSS software version 17. Continuous variables were compared by the Mann-Whitney or Student $t$ test and categorical variables were analyzed by the Fisher exact test or $\chi^{2}$ test. IRB consent was obtained for performing this retrospective study.
Correspondence: Alejandra González Duarte, Department of Neurology and Pshychiatry, Instituto Nacional de Ciencias Médicas y Nutrición Salvador Zubirán, Vasco de Quiroga 15 Sección XVI, Tlalpan 01400, Mexico City, Mexico. E-mail: gonzalezduarte@aol.com.

Key words: neurosyphilis, ocular syphilis, infectious stroke, HIV.

Conflict of interests: the authors declare no potential conflict of interests.

Received for publication: 10 April 2013.

Revision received: 4 July 2013.

Accepted for publication: 10 July 2013.

This work is licensed under a Creative Commons Attribution NonCommercial 3.0 License (CC BYNC 3.0).

(C) Copyright A. González-Duarte and Z. Medina López, 2013

Licensee PAGEPress, Italy

Neurology International 2013; 5:e19

doi:10.4081/ni.2013.e19

\section{Results}

The demographic and laboratory results are summarized in Table 1. Clinical manifestations, HIV status and neurological sequelae are shown in Table 2. Of the 16 patients, 14 (87\%) were men.

\section{Patients description}

Mean age at onset was 44 years old (range: 23-82). Twelve patients (75\%) were HIV positive. HIV stage was B2 in 2 patients, B3 and C2 in one patient each, and $\mathrm{C} 3$ in 8 patients. The mean $\mathrm{CD} 4+$ cell count was 117 cells $/ \mathrm{mm}^{3}$ (range: $3-337$ cells $/ \mathrm{mm}^{3}$ ). In 5 (45\%) patients the diagnosis was made within the first month of HIV diagnosis. Two patients had concomitant venereal diseases (herpetic ulcers and condillomatosis), and one patient had systemic tuberculosis.

\section{Clinical manifestations}

Presenting symptoms were meningitis in 6 (40\%), stroke in 3 (18.7\%) (pons/parietal cortex), ocular manifestations in 4 (27\%), and neuropsychiatric manifestations in 2 (13\%). Neuropsychiatric manifestations consisted of mood irritability, alterations of judgment and behavioral changes in the first patient, while the second patient displayed visual hallucinations and memory impairment. Five additional patients had ocular involvement after a formal ophthalmologic examination. The most common ophthalmologic finding was posterior 
uveitis (choroiditis) in 3 cases, followed by panuveitis (2), retinitis (2), and optic neuritis in one patient. There were no cases of tabes dorsalis.

\section{Laboratory findings}

High VRDL titers were found (serum:1:641:512, CSF:1:4-1:16). Mean CSF parameters were: glucose of $46(35-77 \mathrm{mg} / \mathrm{dL})$, proteins of 99 (36-273 mg/dL) and cells of 21.5 (5-87 cells/ $\mathrm{mm}^{3}$ ).

\section{Treatment}

All patients received IV Penicillin G Benzatine for 14 days. One patient presented a Jarisch-Herxheimer reaction during treatment. Five (33\%) patients had neurologic sequels (Table 2). Clinical manifestations were earlier in patients older than 50 years old with HIV ( $\mathrm{P}=0.049)$.

\section{Discussion}

In our series, the epidemiological background is similar to the reported in the preHAART era. Eighty-seven percent of the patients with neurosyphilis were men, and $73 \%$ were HIV positive men. HIV diagnosis was performed within the first month of neurosyphilis onset in $5(45 \%)$ patients, and syphilis was the clue that precluded HIV testing. As previously reported, ${ }^{2}$ HIV status did not increase the incidence of late forms, nor lead to more severe or later manifestations of neu- rosyphilis. However, patients in C3 stage of HIV had less CSF pleocytosis ( $<5$ cells $/ \mathrm{mm}^{3}$ ) than patients in earlier stages $(\mathrm{P}=0.018)$.

Accurate diagnosis of neurosyphilis is a complex task because the clinical manifestations are polymorphic, and the sensitivity and specificity of supportive laboratory tests are unclear. CSF proteins were moderately elevated in most patients, with a mean of 99 (36273) $\mathrm{mg} / \mathrm{dL}$, as previously reported $(82.8 \pm$ 39.8). Pleocytosis was also moderate, 21 (5-87) cells $/ \mathrm{mm}^{3}$, but lower to similar series $(112.6 \pm 124) .{ }^{2}$ However, all of our patients had a CSF-VDRL positive, while only 10 (62\%) had positive serum-VDRL. CSF-VDRL is very specific, and it is considered to diagnose neurosyphilis in spite of negative serum-VDRL positivity. ${ }^{2}$ Four (25\%) patients had serumVDRL titers above 1:100 (1:256-1:512). These titers suggest that most patients were in the earlier stages of infection.

Meningitis and rash consistent with secondary syphilis (Figure 1) were the most common presentation. Ocular findings were the initial manifestation of syphilis in 3 (23\%) of the HIV patients and in $2(66 \%)$ of the non-HIV patients. When patients were further tested, ocular neurosyphilis was the most common clinical presentation. Generalized panuveitis and optic neuritis were the main findings, in contrast to limited posterior uveitis found in other series. 4 There was a trend towards ocular involvement in HIV stage C3 patients $(\mathrm{P}=0.29)$. Ophthalmologic abnormalities in HIV patients are often attributed to opportunistic infections such as cytomegalovirus or toxoplasmosis, and syphilis is seldom considered.
However, unlike the incidence of CMV retinitis, which decreased after HAART became available, the incidence of ocular syphilis has not decreased. ${ }^{4}$ All of the patients with ocular involvement in this series had high serum VDRL titles.

The meningovascular form consist of endarteritis of vessels anywhere in the CNS resulting in stroke, ${ }^{3}$ and is thought to be a late complication occurring 5 to 12 years after the initial infection with T. Pallidum. ${ }^{3}$ It is estimated that around $3.2 \%$ and up to $15 \%$ of the patients have meningovascular manifestations at some point of the disease. ${ }^{2}$ However, this was somewhat higher in this series, where stroke was present in $18 \%$, as the initial manifestation of

Table 1. Demographic and clinical parameters at entry.

\begin{tabular}{ll} 
Parameters & N=16 \\
Age mean (r) & $44(2382)$ \\
Men & $14(87 \%)$ \\
\hline HIV positive & $12(75 \%)$ \\
VDRL (plasma) & $15(93 \%)(1: 4-1: 512)$ \\
\hline Cerebrospinal fluid & \\
$\quad$ Proteins (mg/dL) & $99(36-273)$ \\
Cells (cells/mm³) & $21(5-87)$ \\
Glucose (mg/dL) & $46(35-77)$ \\
Positive VDRL & $16(100 \%)$ \\
VRDL dilution & $(1: 2-1: 16)$ \\
FTA dilution & $(3-4+)$ \\
Magnetic resonance imaging \\
Meningeal enhacement & $1(6 \%)$ \\
Ischemic lesions & $3(18 \%)$ \\
\hline
\end{tabular}

Table 2. Patient characteristics, HIV status and clinical presentation.

\begin{tabular}{|c|c|c|c|c|c|c|c|c|c|}
\hline ID & Age & Sex & HIV (stage) & $\begin{array}{l}\text { VRDL titers } \\
\text { (plasma) }\end{array}$ & $\begin{array}{l}\text { VRDL titers } \\
\text { (CSF) }\end{array}$ & $\begin{array}{l}\text { Systemic } \\
\text { Mx }\end{array}$ & $\begin{array}{l}\text { CNS } \\
\text { Mx }\end{array}$ & $\begin{array}{l}\text { Oftalmological } \\
\text { finding }\end{array}$ & $\begin{array}{l}\text { Outcome } \\
\text { (live) }\end{array}$ \\
\hline 1 & 42 & M & $\mathrm{P}(\mathrm{C} 3)$ & $1: 512$ & $\mathrm{P}$ & $\mathrm{Sec}$ & Ophtalmologic & Choroiditis & Without sequelae \\
\hline 2 & 80 & $\mathrm{~F}$ & $\mathrm{~N}$ & $1: 4$ & $\mathrm{P}$ & & Ophtalmologic & Panuveitis (b) & With sequelae \\
\hline 3 & 25 & M & $\mathrm{P}(\mathrm{C} 3)$ & $\mathrm{NA}$ & $1: 4$ & $\mathrm{Sec}$ & Meningitis & Panuveitis (b) & Without sequelae \\
\hline 4 & 32 & M & P(B3) & $1: 4$ & $\mathrm{P}$ & JHR & $\begin{array}{l}\text { Meningiovasculitis } \\
\text { (pontine stroke) }\end{array}$ & No & Without sequelae \\
\hline 5 & 30 & M & $\mathrm{P}(\mathrm{C} 3)$ & $1: 64$ & $\mathrm{P}$ & Prim & Meningitis & No & Without sequelae \\
\hline 6 & 29 & M & $\mathrm{P}(\mathrm{C} 3)$ & $1: 64$ & $1: 2$ & Prim & $\begin{array}{l}\text { Meningiovasculitis } \\
\text { (pontine stroke) }\end{array}$ & No & With sequelae \\
\hline 7 & 54 & $\mathrm{~F}$ & $\mathrm{~N}$ & $\mathrm{NA}$ & $1: 4$ & Prim & Ophtalmologic & L Panuveitis & With sequelae \\
\hline 8 & 48 & M & $\mathrm{N}$ & $1: 4$ & $\mathrm{P}$ & Prim & Meningitis & No & Without sequelae \\
\hline 9 & 39 & M & $\mathrm{P}(\mathrm{C} 3)$ & $1: 256$ & $\mathrm{P}$ & Prim & Ophtalmologic & Choroiditis (b) & Without sequelae \\
\hline 10 & 40 & M & $\mathrm{P}(\mathrm{C} 2)$ & $1: 320$ & $1: 4$ & Prim & Neuropsychiatric & Retinitis & Without sequelae \\
\hline 11 & 23 & M & $\mathrm{P}(\mathrm{C} 3)$ & $1: 64$ & $1: 8$ & Prim & Meningitis & Retinitis & With sequelae \\
\hline 12 & 63 & M & $\mathrm{P}(\mathrm{B} 2)$ & NA & $1: 16$ & $\mathrm{Sec}$ & Ophtalmologic & Panuveitis (b) & With sequelae \\
\hline 13 & 82 & M & $\mathrm{P}(\mathrm{C} 3)$ & $\mathrm{NA}$ & $1: 2$ & Prim & Meningitis & Optic neuritis & With sequelae \\
\hline 14 & 45 & M & $\mathrm{P}(\mathrm{B} 2)$ & NA & $\mathrm{P}$ & Prim & Neuropsychiatric & No & Without sequelae \\
\hline 15 & 34 & $\mathrm{M}$ & $\mathrm{P}(\mathrm{C} 3)$ & $\mathrm{NA}$ & $\mathrm{P}$ & Prim & $\begin{array}{l}\text { Meningiovasculitis } \\
\text { (parietal stroke) }\end{array}$ & No & Without sequelae \\
\hline 16 & 33 & M & P(B2) & $1: 256$ & $\mathrm{P}$ & $\mathrm{Sec}$ & Meningitis & Retinitis & Without sequelae \\
\hline
\end{tabular}

P, positive; N, negative; Prim, primary; Sec, secondary; JHR, Jarisch-Herxheimer reaction; (b), bilateral, Mx, manifestations. 
neurosyphilis. In the majority of cases, the middle cerebral artery is usually is affected. Surprisingly, two of the three cases with stoke in this study involved the vertebrobasilar circulation (Figure 2). Stroke of infectious etiology is often difficult to diagnose, and this finding should encourage searching for syphilis in young patients with stroke.

Recently, Mitsonis et al. ${ }^{9}$ described a retrospective series of 81 cases with neurosyphilis. They divided the patients according to the time of presentation, where Period A corresponded to the cases diagnosed before 1984, and Period

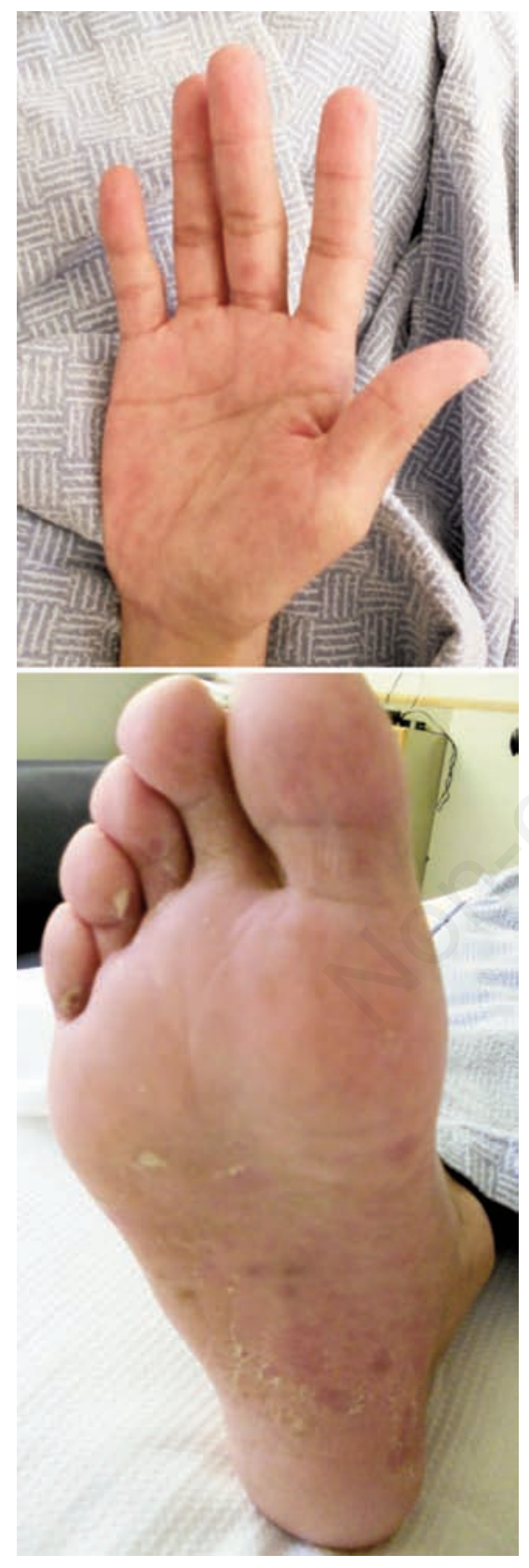

Figure 1. Secondary syphilis at neurological onset.
B to those between 1984 and 2005. The authors found that the former group was more likely to present with typical neurosyphilitic manifestations such as meningovascular disease, while the later group had only a few atypical symptoms plus CSF abnormalities. Interestingly, our cases were more similar to the Period A, because we found meningitis, ocular disturbances and meningovascular manifestations more often, with less frequent cognitive and psychiatric disturbances. According to the authors, the discrepancies in both groups of
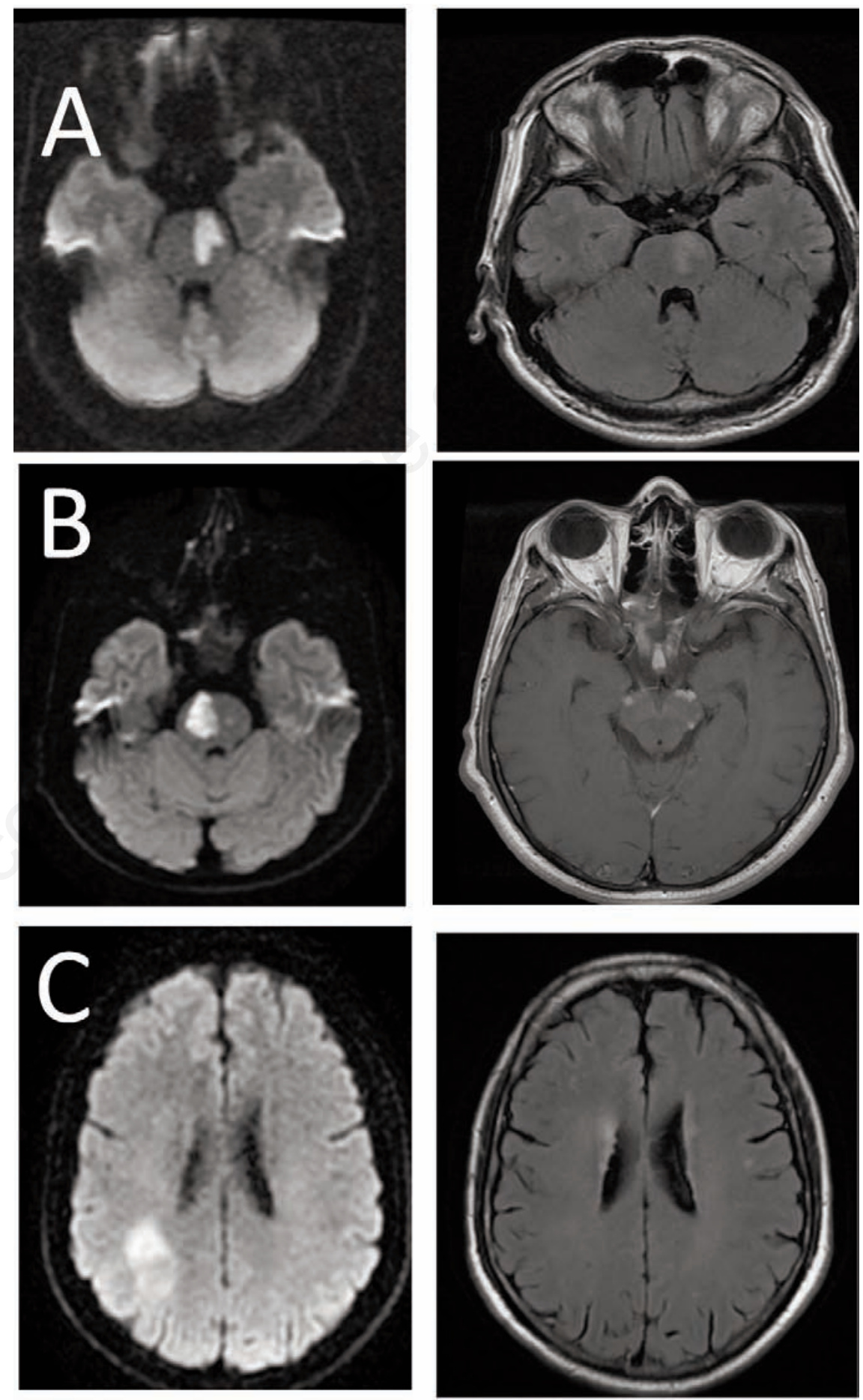

Figure 2. Axial magnetic resonance images. A) Case 4: left hiperintense signal of the pons (DWI/FLAIR); B) Case 6: right hiperintense signal of the pons (DWI) and perimesencephalic enhacement (T1G); C) Case 15: right hyperintense signal on the parietal lobe (DWI/FLAIR). 
their study could be explained by the ongoing widespread use of antibiotics for all kind of infections. Because most cases in our series were diagnosed within the initial diagnosis of HIV and in the early stages of neurosyphilis, we assume that patients were not overtly ill before the diagnosis and therefore did not have indiscriminative use of antibiotics.

\section{Conclusions}

CSF-VDRL was positive in all patients despite being positive only in $62 \%$ of the serum samples. Proteins are usually mild to moderately high, and pleocytosis can be absent in patients with neurosyphilis. When further tested, the main clinical manifestations were ophthalmologic. HIV status did not grant a worse prognosis, non-the-less, because neurosyphilis was more often in HIV patients, we consider that all patients with neurosyphilis and ophthalmologic disease should be tested for HIV.

\section{References}

1. Chao J, Khurana RN, Fawzi A, et. al. Syphilis: reemergence of an old adversary. Ophtalmology 2006;113:2074-9.

2. Goes Gitai L, Samandar J, Massaiti 0 . Neurosyphilis in the age of AIDS: clinical and laboratory features. Neurol Sci 2009;30:465-70.

3. Doherty L, Fenton KA, Jones J, et al. Syphilis: old problem, new strategy. BMJ 2002;20:153-6.

4. Tucker J, Li JZ, Robbins GK, et al. Ocular syphilis among HIV-infected patients: a systematic analysis of the literature. Sex
Transm Infect 2011;87:4-8.

5. 0'Donnell J. Emery C. Neurosyphilis: a current review. Curr Infect Dis Rep 2005;7: 277-84.

6. Ghanem K. Neurosyphilis: a historical perspective and review. CNS Neurosci Ther 2010;16:e157-68.

7. Halperin J. A tale of two spirochetes: Lyme Disease and Syphilis. Neurol Clin 2010;28: 277-91.

8. Zhang SQ, Wan B, Ma XL, et al. Worsened MRI findings during the early period of treatment with penicillin in a patient with general paresis. J Neuroimaging 2008;18: 260-363.

9. Mitsonis CH, Kararizou E, Dimopoulus N, et al. Incidence and clinical presentation of neurosyphilis: a retrospective study of 81 cases. Int J Neurosci 2008;118:1251-7. 